Purdue University Purdue e-Pubs

2012

\title{
The Integration of an Online Module on Student Learning
}

Karen S. Yehle

Purdue University,kyehle@purdue.edu

Karen Chang

Follow this and additional works at: http://docs.lib.purdue.edu/nursingpubs

Part of the Nursing Commons

\section{Recommended Citation}

Yehle, Karen S. and Chang, Karen, "The Integration of an Online Module on Student Learning" (2012). School of Nursing Faculty Publications. Paper 14.

http://dx.doi.org/10.1097/NXN.0b013e31825e1ed6

This document has been made available through Purdue e-Pubs, a service of the Purdue University Libraries. Please contact epubs@purdue.edu for additional information. 
The Integration of an Online Module on Student Learning

\begin{abstract}
Heart failure is a prevalent and costly condition. Patients with better self-management are less likely to be rehospitalized. To enhance students learning of nursing care of patients with heart failure, an online interactive heart failure module was developed and integrated into a medicalsurgical nursing course. The purpose of this study was to examine whether the integration of an online heart failure module improved baccalaureate nursing students' heart failure selfmanagement knowledge. A pretest/ posttest design was used to examine the effects of student knowledge of heart failure self-management following implementation of an online module. Among 235 students, significant improvement of heart failure self-management knowledge was observed $(\mathrm{p}<0.05)$. The mean posttest scores ranged from 13.82 to 15.93 . Students had problems mastering knowledge of weight monitoring, use of NSAIDS, symptoms to report to physicians, and potassium-based salt substitutes. These findings were similar to four studies examining nurses' knowledge of heart failure. Students and nurses have difficulty mastering similar heart failure education concepts. An additional strategy, such as simulated or case scenarios, needs to be developed to help nurses and nursing students master all key concepts of heart failure self-management.
\end{abstract}

\title{
Key Words
}

Nursing Education, Baccalaureate Nursing Student, Computer-Assisted Instruction, Multimedia, Heart Failure 


\section{Introduction}

Heart failure (HF) is a condition that affects 5.8 million Americans and is expected to cost $\$ 39.2$ billion in $2010^{1,2}$. It is the most common reason for hospitalization among those older than 65 years, with over one million hospitalizations in 2006, and an estimated 670,000 new cases expected ${ }^{3}$. Clinical practice guidelines recommend that patients with HF and their family members should receive education about heart failure self-management ${ }^{4}$. Patients who are better at heart failure self-management are less likely to be re-hospitalized ${ }^{5}$.

However, studies reported that nurses did not have adequate heart failure selfmanagement knowledge and patients did not receive adequate heart failure self-management

education. Four studies that used the Heart Failure Knowledge questionnaire ${ }^{6}$ identified similar findings: nurses had inadequate knowledge regarding dry/ideal weight, non-steroidal antiinflammatory drug (NSAID), short-term dizziness, asymptomatic hypotension, and potassiumbased salt substitutes ${ }^{6-8}$. One study examined patient perceptions of heart failure selfmanagement education ${ }^{9}$ and found that among 779 patients, $27.5 \%$ did not receive education about shortness of breath or fatigue; $26.2 \%$ about salty foods; $42.1 \%$ about monitoring daily weight; and $53.1 \%$ about limiting fluid intake. Nurses are the principle providers of patient education. When nurses do not have adequate knowledge of heart failure self-management, they have limited abilities to provide patient education for heart failure self-management.

\section{An Online Heart Failure Module}

To prepare future nurses understanding of heart failure self-management knowledge, we collaborated with the university's information technology staff and developed an interactive multimedia online heart failure module. The online module was designed to enable student nurses learn pertinent information related to heart failure prior to caring for a patient with this 
condition. This module consisted of four links related to heart failure (Figure 1): (a) content, (b) quiz, (c) printable document, and (d) a case study. The learning objectives of this module were to:

- Recognize the importance of heart failure in terms of etiology, incidence, and cost.

- Relate the signs and symptoms of heart failure to its pathophysiology.

- Distinguish between the classification systems for heart failure.

- Correlate assessment findings to pathophysiology and treatment of heart failure.

- Identify specific tests used in diagnosis and management of heart failure.

- Differentiate between classifications and actions of drugs used for heart failure.

- Apply the nursing process to identify common nursing diagnoses, interventions, and evaluations related to patients with heart failure.

- Anticipate the educational needs of patients and their family members.

The design of the module included multimedia (audios, animations), interactive activities, a case study, quiz questions, and hyperlinks. Multimedia and interactive activities were used to facilitate learning; self-assessment quiz questions were used to reinforce heart failure knowledge presented in the module, and a case study was used to promote critical thinking skills. Best practices for course organization and navigation were used to develop the online module ${ }^{10}$.

The initial version was of the online module was primarily text-based with some hyperlinks and graphics. Multimedia (audios, animations), interactive activities, a case study, quiz questions, hyperlinks, and updated content were added to the module after two semesters. An animation of a healthy heart and a diseased heart was added to the module (Figure 2). Students clicked on "Stop" or "Play" button to see the dynamics of blood flow and kinesis of the chambers. 
The content of the module was derived from current, reliable, and credible, heart failure literature, such as the American Heart Association/Heart Failure Society of America guidelines, medical-surgical nursing and nursing diagnoses textbooks, and heart failure websites. Key heart failure self-management information that is important for patient education was incorporated in the module.

The content was organized into three levels (topics, subtopics, and key content) for easy navigation and quick access of information. Each topic or subtopic is one webpage. A total of 20 webpages was included in the content link of the Heart Failure Module.

The topics in the first level are: Objectives, Definition, Incidence, Etiology, Pathophysiology, Diagnostic Tests, Assessment, Classification Systems, Interventions, and Resources (Figure 1). The topics of Etiology, Pathophysiology, and Interventions have subtopics. The subtopics of Etiology include: Coronary Artery Disease, Hypertension, and Valvular Disease. The subtopics of Pathophysiology include: Stroke Volume Determinants, Compensatory Mechanisms, and Types of Heart Failure. The subtopics of Intervention include: Nursing, Pharmacological, Surgical, and Experimental. Key content is provided under topics and subtopics. For example, the subtopic of Nursing included Nursing Diagnoses, Goals, Nursing Interventions, Patient Outcomes/Evaluations, and Ethics and End of Life Care. A “+” sign (with embedded subtopics) or a "_" sign (with expanded subtopics) was placed before each topic. Users could select a specific topic or subtopic to view key content.

\section{Methods}

\section{Design}


A descriptive pretest/posttest design was used to examine whether the integration of an online heart failure module improved students' heart failure self-management knowledge. Specific research questions included:

1. Were there differences in students' heart failure self-management knowledge before and after the integration of an online heart failure module?

2. Were there differences in students' heart failure self-management knowledge between the initial and revised online heart failure module?

3. What areas of heart failure self-management knowledge did students master and show deficiencies in?

Student knowledge of heart failure was measured by the Heart Failure Knowledge questionnaire ${ }^{6}$. Permission to use the questionnaire was obtained prior to the study.

\section{Heart Failure Knowledge Questionnaire}

The Heart Failure Knowledge questionnaire was developed to measure nurses' knowledge of key heart failure self-management information, which is important for education of patients prior to hospital discharge ${ }^{6}$. Face and content validity was established by four content experts. The questionnaire has 20 true/false or yes/no questions, including exercise (2 items), signs and symptoms of worsening heart failure (6 items), medications ( 2 items), diet (3 items), and fluid status/weight (7 items). Total scores for the entire instrument range from 0 to 20; higher scores indicate better knowledge of heart failure self-management. Nurses who cared for heart failure patients regularly are expected to have a total score of at least 17 to 18 of 20 (80$85 \%$ correct).

\section{Procedure}


Students enrolled in a junior level medical-surgical nursing course of a baccalaureate nursing program in the Midwestern United States were included in the study during the four semester data collection period. The implementation of this online module was designed to promote active, collaborative learning. Strategies used to integrate this module as follows:

- Replaced the didactic heart failure lecture in the medical-surgical nursing course with the online module. Students were directed to complete the online module, including a case study (see sample questions in Table 1) prior to the heart failure class.

- During the 2 hours class period, students worked in groups to discuss patient problems related to the online case study in the module and then reported group solutions to the class.

- Faculty facilitated the group discussion and clarified misconceptions or incorrect information that students presented.

Students completed the Heart Failure Knowledge questionnaire in class at the beginning of the semester, prior to clinical experiences, and again at the end of semester. Approval from the Institutional Review Board was received prior to beginning the study. Participation was not part of the course grade. Use of the module and the HFKQ was part of the course assignments. Data was de-identified when it was entered into an excel spread sheet and imported into SPSS for analysis

Students who completed both the pretest and posttest of the Heart Failure Knowledge questionnaire were included in the sample. The online module was available to students immediately after the pretest and throughout the semester. Students could access the online module and complete the self-quiz an unlimited number of times. 


\section{Analyses}

A paired t-test was used to examine the differences in students' heart failure selfmanagement knowledge before and after the online heart failure module. Analysis of variance (ANOVA) was used to examine the differences in students' heart failure self-management between the initial and revised online module. The McNemar test was used to identify which areas of heart failure self-management knowledge the students mastered. The McNemar test is a non-parametric test to examine the difference between pretest and posttest scores in the proportion of students answering each item correctly.

\section{Results}

The sample consisted of 254 undergraduate nursing students during the four semester data collection period. The majority of the students were 20 years old and female. The pretest and posttest were completed by 235 students. The number of students with complete data varied across semesters. Among 254 students, 49 of 60 students (81.7\%) completed in the first semester, 43 of 47 students $(91.5 \%)$ completed in the second semester, 73 of 75 students (97.3\%) completed in the third semester, and 70 of 72 students $(97.2 \%)$ completed in the fourth semester.

\section{Students' Heart Failure Self-Management Knowledge}

Mean pretest and posttest scores showed that nursing students had significant improvement of heart failure self-management knowledge each semester (Table 2, $\mathrm{p}<0.05$ ). Mean posttest student scores ranged from 13.82 to 15.93 . Students using the revised module had a higher mean heart failure self-management knowledge score than students using the initial module (ANOVA, $1.65 \pm 1.98$ vs. $0.85 \pm 2.23, \mathrm{p}=0.004)$.

The percentage of students with correct responses to the Heart Failure Knowledge questionnaire at posttest varied widely (Table $3,12.2 \%$ to $98.8 \%$ ). Ten of the 20 items had 
$>90 \%$ correct responses at posttest (92.1\% to 98.8\%). Among high-scoring items, three had significant improvement at posttest: "Patients should drink plenty of fluid each day"; "It is acceptable to remove fluid restrictions when patients are thirsty," and "Adding an extra pillow to relieve orthopnea does not indicate worsening condition" $(\mathrm{p}<0.01)$. Scores for the other highscoring items did not improve at posttest, suggesting a ceiling effect.

Of the other 10 items, three had mean correct responses between $74.7 \%$ and $79.5 \%$ at posttest. Of the three items, two items had significantly higher scores at posttest $(\mathrm{p} \leq 0.001)$ : “paroxsymal nocturnal dyspnea does not indicate worsening condition" and "patients should decrease activity and avoid active exercise." Seven items had mean correct responses ranging from $12.2 \%$ to $60.7 \%$. Three of these seven items improved significantly at posttest $(\mathrm{p}<0.05)$ : "is acceptable to eat lean deli meats", "is acceptable to take K-based salt substitute; and "should notify doctor for nonsymptomatic blood pressure of 80/56." Four of the seven items did not improvement at posttest.

\section{Discussion}

Results demonstrate that students had significantly higher heart failure self-management knowledge scores at the end of each semester, which indicates that the online module with selfstudy mode had a positive effect on students' learning of heart failure self-management. However, the overall scores were well below the expected and actual score range for nurses caring for patients with heart failure in a hospital or home care settings ${ }^{6}$. For online learning to be effective, students need to take an active role ${ }^{11}$. This online heart failure module incorporated active learning strategy (e.g. group case study work, discussions) in its design and implementation. However, many factors could influence learning, such as motivation to learn, number of clinical experiences with heart failure patients, past practice in educating patients 
about heart failure, personal experiences (for example, loved ones) of care of heart failure, amount of time spent on the online module, or information learned from the instructor when discussing heart failure in class. Future studies should include these factors to examine the effects of an online module on learning about heart failure and self-care.

Students who used the revised module had significantly higher scores than students who used the initial module. The revised module had similar content as the initial module. Improved design and additional multimedia and interactive activities in the revised module could have positively influenced student learning.

Mean posttest scores (Table 2) reflect that students mastered some content and have deficiencies in other areas related to heart failure self-management ${ }^{6}$. At posttest, students mastered (> 90\% with correct answer) ten of 20 heart failure self-management items and had low scores in seven items (mean item scores $<70 \%$; Table 3). Five low scoring items were consistent with low scoring items reported in studies that examined nurses' knowledge of heart failure (Table 4) ${ }^{6-8}$. Self-management content related to these five items is essential for nurses to understand before educating patients about heart failure self-management. These items reflect themes that are commonly associated with activities of daily living. Nurses working with heart failure patients should understand that patients:

- Should compare daily weight with individualized goal weight (dry weight) rather than the weight of the previous day

- Do not need to call physicians for asymptomatic low blood pressure and very short term $(<15$ minutes) dizziness

- Should avoid NSAIDs when experiencing aches and pains because the use of NSAIDs is associated with the occurrence of heart failure relapse ${ }^{12,13}$ 
- Should avoid potassium-based substitutes because angiotensin converting enzyme inhibitors, angiotensin receptor blockers and aldosterone antagonists used in heart failure management may raise the serum potassium level ${ }^{6}$

It is crucial that nurses who care for patients with heart failure have adequate knowledge so that they can provide suitable patient education and assess patient's knowledge of heart failure self-management. Delivery of heart failure education is associated with improved self-care post discharge and improved all-cause death or re-hospitalization at six months (Koelling, 2005), which in turn can decrease healthcare costs.

This study shows that nurses and nursing students have similar difficulties mastering the content of heart failure self-management (i.e., monitoring daily weight, response to low blood pressure, avoidance of NSAIDs and potassium-based substitutes).

The results of this study are limited in one Midwest baccalaureate program in the United States. This study used a pre- and post-test to examine student mastering of knowledge related to heart failure and did not have a control group to compare the true effectiveness of the online module on student learning. The course management system tracked logged on time, but not actual time that students spent in the online heart failure learning module. Thus, this study did not examine the efficiency of this module on student learning. The effects of this online module on students' competency in providing patient education was not examined, nor were student's personal factors such as motivation, effort, and clinical experiences. These factors could affect student learning of heart failure self-management.

\section{Conclusion}

The online module with self-directed learning appears to have a positive effect on student learning of heart failure self-management. However, students, similarly to nurses working in 
cardiology, have difficulty mastering some key concepts related to heart failure self-

management. It is important for nurses to help patients better manage their heart failure. An additional strategy, such as simulated or case scenarios, needs to be developed to help nurses and nursing students master all key concepts of heart failure self-management. 


\section{References}

1. Lloyd-Jones D, Adams RJ, Brown TM, et al. Heart disease and stroke statistics--2010 update: A report from the American Heart Association. Circulation. Feb 23 2010;121(7):e46-e215.

2. Roger VL, Go AS, Lloyd-Jones DM, et al. Heart disease and stroke statistics--2011 update: a report from the American Heart Association. Circulation. Feb 1 2011;123(4):e18-e209.

3. Liu L. Changes in cardiovascular hospitalization and comorbidity of heart failure in the United States: findings from the National Hospital Discharge Surveys 1980-2006. Int J Cardiol. May 19 2011;149(1):39-45.

4. Lindenfeld J, Albert NM, Boehmer JP, et al. HFSA 2010 Comprehensive Heart Failure Practice Guideline. J Card Fail. Jun 2010;16(6):e1-194.

5. Jovicic A, Holroyd-Leduc JM, Straus SE. Effects of self-management intervention on health outcomes of patients with heart failure: A systematic review of randomized controlled trials. BMC Cardiovascular Disorders. 2006;6:43.

6. Albert NM, Collier S, Sumodi V, et al. Nurses's knowledge of heart failure education principles. Heart Lung. Mar-Apr 2002;31(2):102-112.

7. Washburn SC, Hornberger CA, Klutman A, Skinner L. Nurses' knowledge of heart failure education topics as reported in a small midwestern community hospital. $J$ Cardiovasc Nurs. 2005;20(3):215-220.

8. Willette EW, Surrells D, Davis LL, Bush CT. Nurses' knowledge of heart failure selfmanagement. Prog Cardiovasc Nurs. 2007;22(4):190-195.

9. Baker DW. A telephone survey to measure communication, education, self-management, and health status for patients with heart failure: the Improving Chronic Illness Care Evaluation (ICICE). J Card Fail. 2005;11(1):36.

10. CANnect. Course Organization and Navigation. Available at: http://sloanconsortium.org/cannect/projectone/best-practices/course-organization.php.

11. Mancuso-Murphy J. Distance education in nursing: An integrated review of online nursing students' experiences with technology-delivered instruction. J Nurs Educ. Jun 2007;46(6):252-260.

12. Feenstra J, Heerdink ER, Grobbee DE, Stricker BH. Association of nonsteroidal antiinflammatory drugs with first occurrence of heart failure and with relapsing heart failure: the Rotterdam Study. Arch Intern Med. Feb 11 2002;162(3):265-270.

13. Page J, Henry D. Consumption of NSAIDs and the development of congestive heart failure in elderly patients: An underrecognized public health problem. Arch Intern Med. Mar 27 2000;160(6):777-784. 